\title{
Diversity for security: case assessment for FPGA-based safety-critical systems
}

\author{
Vyacheslav Kharchenko ${ }^{1,2}$, Oleg Illiashenko ${ }^{1, a}$ \\ ${ }^{1}$ National Aerospace University "KhAl", 61070 Kharkiv, Ukraine \\ ${ }^{2}$ Centre for Safety Infrastructure Oriented Research and Analysis, 61085 Kharkiv, Ukraine
}

\begin{abstract}
Industrial safety critical instrumentation and control systems (I\&Cs) are facing more with information (in general and cyber, in particular) security threats and attacks. The application of programmable logic, first of all, field programmable gate arrays (FPGA) in critical systems causes specific safety deficits. Security assessment techniques for such systems are based on heuristic knowledges and the expert judgment. Main challenge is how to take into account features of FPGA technology for safety critical I\&Cs including systems in which are applied diversity approach to minimize risks of common cause failure. Such systems are called multi-version (MV) systems. The goal of the paper is in description of the technique and tool for casebased security assessment of MV FPGA-based I\&Cs.
\end{abstract}

\section{Introduction}

\subsection{Four challenges for I\&C safety assessment and assurance}

Industrial safety critical instrumentation and control systems (I\&Cs) such as reactor trip systems, on-board aviation systems, railway blocking and signaling systems, etc. are facing more with information (in general and cyber, in particular) security threats and attacks. It concerns most sensitive in point of view safety nuclear domain [1]. Nowadays there is a gap in understanding how to assess safety of industrial I\&Cs considering the following:

- firstly, the security issues; security related threats are more and more challengeable for safety critical application. As a result security informed safety conception is intensively developed the last years, in particular for NPP I\&Cs [2];

- secondly, the features of FPGA technology and FPGA-based systems as a specific target for intruders. Security aspects for FPGA design and implementation are analyzed in [3-5]. These works allow to systemize different vulnerabilities and threats, and better to understand which of them should be taken into account to assure security;

- thirdly, an application of diversity approach as a mean of minimizing common cause failure risks. In this case two (or more) channels are used in different combinations for obtaining the needed functionality and ensuring of required level of safety. Techniques of development and safety assessment of FPGA-based multi-version industrial systems (MVI\&Cs) are researched in [6-8]. However, it is required to analyze influence and features of diversity application in point of view security;

- fourthly, using of case-based proved paradigm. Really, to assure trustworthiness of security assessment for such extremely complex systems, more formalized (and independent in sense of expert errors and uncertainties) techniques are required.

\subsection{Researched domains. Goal of the paper}

The paper represents research results in the domains of safety, security, diversity and FPGA with representation of methodology of cybersecurity assessment based on cases. The figure 1 shows research fields and the targeted area encircled by red line. Additionally, dashed line describes area of case-based approach application to assessment of safety and security.

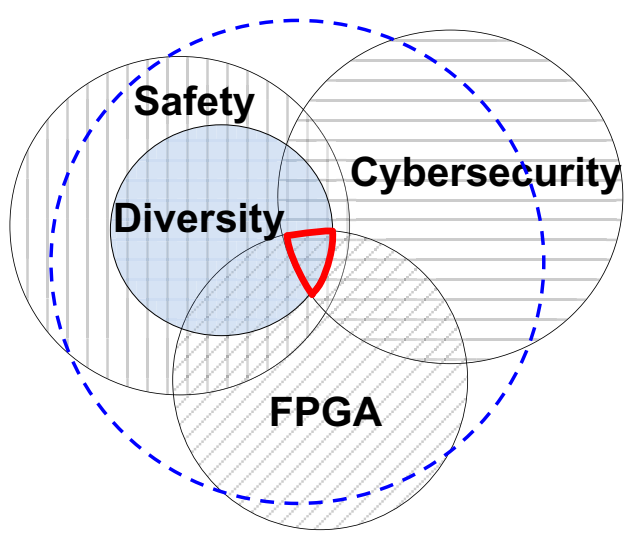

Figure 1. Targeted area of research

\footnotetext{
a Corresponding author: o.illiashenko@csn.khai.edu
} 
Another research aspect is providing effective risk mitigation strategy by use of countermeasures (see Figure 2 where area of countermeasures for FPGA-based MV I\&C systems is encircled by red as well, and dashed line describes area of case-based approach application to choice and prove effectiveness of countermeasures).

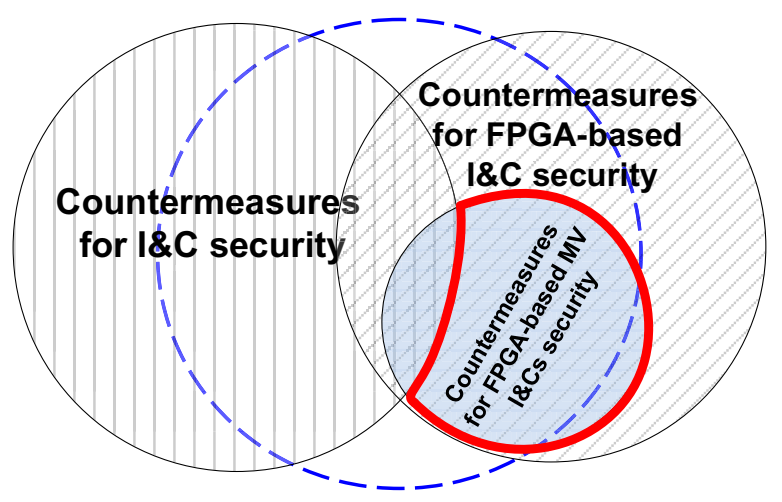

Figure 2. Targeted area for countermeasures.

Thus, goal of the paper is to suggest technique and tool for case-based security assessment of FPGA-based MVI\&Cs. Structure of the paper is following.

Second section describes normative base (ISO, IEC and IAEA standards), classification and analysis of application of diffrent diversity kinds for safety and security assessment and assurance for FPGA-based I\&Cs.

Third section is dedicated to case development and descridiscusses an example of ASAC application for security analysis and assessment.

The last section concludes the paper and presents directions of future researches.

\section{Diversity for safety and security of FPGA-based I\&Cs}

Diversity is a part of more general principle D3 (Defensein-Depth\&Diversity) [8] applied to provide trusted, faultand intrusion-tolerant design and operation of I\&Cs. Defense-in-Depth is a horizontal/sequential echelon of defense, diversity is a vertical/parallel part of once [11].

\subsection{Diversity related standards for safety and security}

There are a lot of international standards and national guides containing requirements for implementation and assessment of diversity. Among them are:

a) IEC standards:

- IEC 61513:2001. NPPs - I\&Cs important to safety general requirements for systems;

- IEC 60880 2006. NPPs - I\&Cs important to safety SW aspects for computer-based systems performing category A functions;

- IEC $61508: 2011$. Functional Safety of Electrical/Electronic/Programmable Electronic Safetyrelated Systems; b) IAEA standards :

- IAEA NS-G-1.1:2001. Software for Computer Based Systems Important to Safety in NPPs;

- IAEA NS-G-1.3:2002. I\&Cs important to safety in NPPs;

- IAEA NP-T-1.5:2009. Protecting against CCFs in Digital I\&C Systems of NPPs ;

c) IEEE and NUREG (USA) standards :

- IEEE std.7-4.3.2:2003. IEEE standard criteria for digital computers in safety systems of NPPs;

- NUREG/CR-7007:2009. Diversity Strategies for NPP I\&C Systems, NUREG/CR-7007 ORNL/TM2009/302.

d) National guides and norms :

- DI\&C-ISG-02, Diversity and Defense-in-Depth Issues, Interim Staff Guidance (USA);

BTP 7-19, Guidance for Evaluation of D\&DiD In Digital I\&C Systems (USA);

- NP 306.5.02/3.035. Requirement on nuclear and radiation safety for I\&Cs important to safety in NPPs (Ukraine), etc.

There are standards for other critical domains where diversity as an approach is postulated or requirements to its application are described. For example, requirements to diversity for automotive systems are determined by standard IEC 26262. This standard contains requirements regarding application of software and hardware diversity for on-board vehicle systems.

Generally, the standards are not enough detailed to make all necessary decisions concerning diversity: type of diversity selection and combining, process and product diversity volume assessing and grounding, etc. It is very importanty that they do not take into account two issues :

- features of FPGA technology what complicates their application and

- security issues for safety assessment.

\subsection{Assessment of safety and security of FPGA- based I\&Cs}

\subsubsection{Comparison of diversity for SW- and FPGA- based I\&Cs}

FPGA-based technology provides new possibilities for implementation of diversity principle and additional options $[7,8]$. The features of FPGA technology increase a number of diversity kinds and enlarge a set of possible diversity-oriented decisions.

General diversity classification scheme was presented by "cube of diversity" with three coordinates: "stage of the life cycle" - "level of project decisions" and "type of version redundancy" [8]. Using this classification we can analyse safety and security issues for FPGA-based systems and traditional SW-based I\&Cs, first of all, for NPPs.

Table 1 summarizes variety of diversity attributes from NUREG-CR/7007:2009 for NPP I\&Cs and their accordance with kinds of version redundancy of FPGAbased systems. 
Table 1. Diversity attributes and correspondent FNI\& Cs version redundancy kinds.

\begin{tabular}{|c|c|}
\hline DIVERSITY ATTRIBUTES (NUREG-CR/ 7007:2009) & $\begin{array}{l}\text { KINDS OF VERSION REDUNDANCY } \\
\text { (FPGA-BASED I\&Ss) }\end{array}$ \\
\hline Design & Diversity of electronic elements (EE) \\
\hline Different technologies & $\begin{array}{l}\text { Different manufacturers of EEs; } \\
\text { Different technologies of EEs production }\end{array}$ \\
\hline Different approaches within a technology & Different technologies of EEs production \\
\hline Different architectures within a technology & Different families of EEs \\
\hline Equipment Manufacturer & Diversity of electronic elements (EE) \\
\hline $\begin{array}{l}\text { Different manufacturers of fundamentally different } \\
\text { equipment designs }\end{array}$ & Different manufacturers of EEs \\
\hline $\begin{array}{l}\text { Same manufacturer of fundamentally different } \\
\text { equipment designs }\end{array}$ & Different families of EEs \\
\hline Different manufacturers of same equipment design & Different manufacturers of EEs \\
\hline $\begin{array}{l}\text { Same manufacturer of different versions of the same } \\
\text { equipment design }\end{array}$ & Different EEs of the same family \\
\hline Logic Processing Equipment & $\begin{array}{c}\text { Diversity of project development } \\
\text { languages }\end{array}$ \\
\hline \multicolumn{2}{|l|}{ Different logic processing architectures } \\
\hline \multicolumn{2}{|l|}{ Different logic processing versions in same architecture } \\
\hline Different component integration architectures & $\begin{array}{l}\text { Joint use of graphical scheme language } \\
\text { and hardware description language } \\
\text { (HDL) }\end{array}$ \\
\hline Different data flow architectures & $\begin{array}{l}\text { Joint use of graphical scheme language } \\
\text { and HDL }\end{array}$ \\
\hline Function & Diversity of CASE-tools \\
\hline $\begin{array}{l}\text { Different underlying mechanisms to accomplish safety } \\
\text { function }\end{array}$ & $\begin{array}{l}\text { Combination of couples of diver se CASE } \\
\text { tools and SSs }\end{array}$ \\
\hline $\begin{array}{l}\text { Different purpose, function, control logic, or actuation } \\
\text { means of same underlying mechanism }\end{array}$ & Different SSs \\
\hline \multicolumn{2}{|l|}{ Different response time scale } \\
\hline Life-Cycle & Diversity of CASE-tools \\
\hline Different design companies & $\begin{array}{l}\text { Combination of couples of diver se CASE- } \\
\text { tools and HDLs }\end{array}$ \\
\hline Different management team s within the same company & $\begin{array}{l}\text { Combination of diver se CASE-tools and } \\
\text { HDLs }\end{array}$ \\
\hline Different designers, engineers, and/or programmers & Different HDLs \\
\hline \multicolumn{2}{|l|}{ Different implementation/validation teams } \\
\hline Signal & $\begin{array}{l}\text { Diversity of CASE-tools, Diversity of } \\
\text { scheme specification (SS) }\end{array}$ \\
\hline $\begin{array}{l}\text { Different reactor or process parameters sen sed by } \\
\text { different physical effect }\end{array}$ & $\begin{array}{l}\text { Combination of couples of diverse CASE } \\
\text { tools and SSs }\end{array}$ \\
\hline \multicolumn{2}{|l|}{$\begin{array}{l}\text { Different reactor or process parameters sen sed by the } \\
\text { same physical effect }\end{array}$} \\
\hline \multicolumn{2}{|l|}{$\begin{array}{l}\text { The same process parameter sensed by a different redundant } \\
\text { set of similar sensors }\end{array}$} \\
\hline Logic & $\begin{array}{l}\text { Diversity of CASE-tools, Diversity of } \\
\text { scheme specification (SS) }\end{array}$ \\
\hline Different algorithms, logic, and program architecture & $\begin{array}{l}\text { Combination of couples of diverse CASE- } \\
\text { tools and HDLs }\end{array}$ \\
\hline Different timing or order of execution & Different CASE tools configurations \\
\hline Different runtime environments & Different CASE tools \\
\hline Different functional representations & Different HDLs \\
\hline
\end{tabular}




\subsubsection{Diversity and security}

Table 2 shows results of research on diversity attributes from NUREG-CR/7007 which could be applied to mitigate CCF in diverse SW- and HW/FPGA-based systems with the same vulnerabilities in both versions. Different vulnerabilities in both versions have four grades: $\mathrm{VH}$ - very high, $\mathrm{H}$-high, $\mathrm{M}$ - medium, $\mathrm{L}$ - low.

Gradation is based on risk reduction after appliance of a certain diversity attribute. In this case diversity is considered as a countermeasure for elimination of harmful consequences after successful attacks.

\subsection{Diversity as a countermeasure}

Table 3 summarizes some attacks on FPGA-based I\&Cs and results of security assessment using IMECA-analysis $[2,8]$. Countermeasures are employed to thwart such tampering attacks. The table contains countermeasures strategies which could be applied as a requirements from Regulatory Guide 5.71:2010 (Cyber Security Programs For Nuclear Facilities, U.S. NRC) to eliminate the attack causes and, moreover, FPGA-based MV I\&Cs diversity kind and its attributes as a countermeasures.

Thus diversity of FPGA-based MV I\&Cs is reviewed as a countermeasure and mitigation strategy for ensuring of security and safety of systems. Criticality matrix (see Fig.3) shows how application of different FPGA-based I\&Cs diversity kinds and its attributes will decrease the level of overall risk.

\section{Security case development}

\subsection{Advanced security assurance case}

The idea of cybersecurity case for evaluation of security of MV I\&Cs lays in appliying of Advanced Security Assurance Case ASAC proposed by [9] which is built taking into account requirements to version kinds of systems. 
Table 2. Diversity attributes as a countermeasure.

\begin{tabular}{|c|c|c|c|c|}
\hline \multirow{4}{*}{ DIVERSITY ATTRIBUTES (NUREG-CR/ 7007:2009) } & \multicolumn{4}{|c|}{ VULNERABILITIES } \\
\hline & \multicolumn{2}{|c|}{ Software } & \multicolumn{2}{|c|}{ Hardware } \\
\hline & \begin{tabular}{c|} 
common \\
vulnerabilit
\end{tabular} & $\begin{array}{c}\text { different } \\
\text { vulnerabilitie }\end{array}$ & \begin{tabular}{c|} 
common \\
vulnerabilit
\end{tabular} & $\begin{array}{c}\text { different } \\
\text { vulnerabilitie }\end{array}$ \\
\hline & $\mathbf{y}$ & $\mathbf{s}$ & $\mathbf{y}$ & $\mathbf{s}$ \\
\hline \multicolumn{5}{|l|}{ Design } \\
\hline Different technologies & $\mathrm{H}$ & $\mathrm{H}$ & $\mathrm{H}$ & $\mathrm{H}$ \\
\hline Different approaches within a technology & $\mathrm{M}$ & $\mathrm{M}$ & $\mathrm{M}$ & $\mathrm{M}$ \\
\hline Different architectures within a technology & L & L & $\mathrm{L}$ & $\mathrm{L}$ \\
\hline \multicolumn{5}{|l|}{ Equipment $M$ anufacturer } \\
\hline $\begin{array}{l}\text { Different manufacturers of fundamentally } \\
\text { different equipment designs }\end{array}$ & $\mathrm{H}$ & $\mathrm{H}$ & $\mathrm{H}$ & $\mathrm{H}$ \\
\hline $\begin{array}{l}\text { Same manufacturer of fundamentally different } \\
\text { equipment designs }\end{array}$ & HM & HM & $\mathrm{HM}$ & HM \\
\hline $\begin{array}{l}\text { Different manufacturers of same equipment } \\
\text { design }\end{array}$ & M & M & M & M \\
\hline $\begin{array}{l}\text { Same manufacturer of different versions of the } \\
\text { same equipment design }\end{array}$ & L & L & L & L \\
\hline \multicolumn{5}{|l|}{ Logic Processing Equipment } \\
\hline Different logic processing architectures & $\mathrm{H}$ & $\mathrm{H}$ & $\mathrm{H}$ & $\mathrm{H}$ \\
\hline $\begin{array}{l}\text { Different logic processing versions in same } \\
\text { architecture }\end{array}$ & HM & HM & HM & HM \\
\hline Different component integration architectures & M & $\mathrm{M}$ & $\mathrm{M}$ & $\mathrm{M}$ \\
\hline Different data flow architectures & $\mathrm{L}$ & $\mathrm{L}$ & $\bar{L}$ & $\mathrm{~L}$ \\
\hline \multicolumn{5}{|l|}{ Function } \\
\hline $\begin{array}{l}\text { Different underlying mechanisms to accomplish } \\
\text { safety function }\end{array}$ & $\mathrm{H}$ & $\mathrm{H}$ & $\mathrm{H}$ & $\mathrm{H}$ \\
\hline $\begin{array}{l}\text { Different purpose, function, control logic, or } \\
\text { actuation means of same underlying mechanism }\end{array}$ & M & M & M & M \\
\hline Different response time scale & $\mathrm{L}$ & $\mathrm{L}$ & $\mathrm{L}$ & $\mathrm{L}$ \\
\hline \multicolumn{5}{|l|}{ Life-Cycle } \\
\hline Different design companies & $\mathrm{H}$ & $\mathrm{H}$ & $\mathrm{H}$ & $\mathrm{H}$ \\
\hline $\begin{array}{l}\text { Different management teams within the same } \\
\text { company }\end{array}$ & HM & $\mathrm{HM}$ & $\mathrm{HM}$ & HM \\
\hline $\begin{array}{l}\text { Different designers, engineers, and/ or } \\
\text { programmers }\end{array}$ & M & M & M & M \\
\hline Different implementation/validation teams & $\mathrm{L}$ & $\mathrm{L}$ & $\mathrm{L}$ & $\mathrm{L}$ \\
\hline \multicolumn{5}{|l|}{ Signal } \\
\hline $\begin{array}{l}\text { Different reactor or process parameters sensed } \\
\text { by different physical effect }\end{array}$ & $\mathrm{H}$ & $\mathrm{H}$ & $\mathrm{H}$ & $\mathrm{H}$ \\
\hline $\begin{array}{l}\text { Different reactor or process param eters sensed } \\
\text { by the same physical effect }\end{array}$ & M & M & M & M \\
\hline $\begin{array}{l}\text { The same process parameter sensed by a } \\
\text { different redundant set of similar sensors }\end{array}$ & L & L & L & L \\
\hline \multicolumn{5}{|l|}{ Logic } \\
\hline $\begin{array}{l}\text { Different algorithms, logic, and program } \\
\text { architecture }\end{array}$ & $\mathrm{H}$ & $\mathrm{H}$ & $\mathrm{H}$ & $\mathrm{H}$ \\
\hline Different timing or order of execution & HM & HM & HM & HM \\
\hline Different runtime environments & $\mathrm{M}$ & $\mathrm{M}$ & $\mathrm{M}$ & $\mathrm{M}$ \\
\hline Different functional representations & $\mathrm{L}$ & $\mathrm{L}$ & $\mathrm{L}$ & $\mathrm{L}$ \\
\hline
\end{tabular}




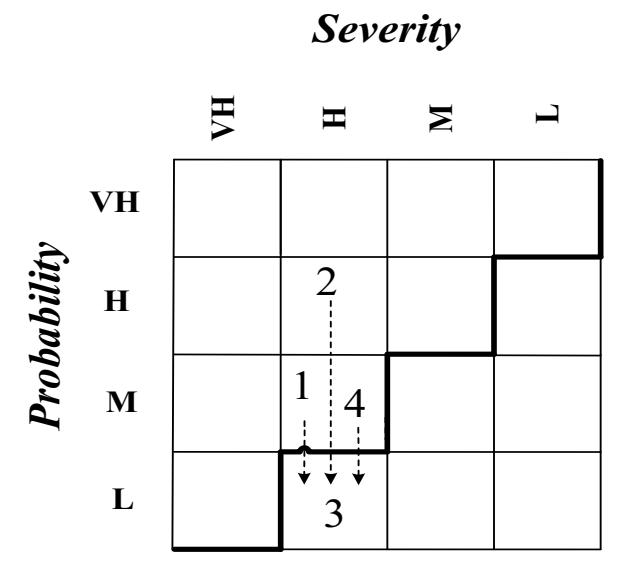

Figure 3. Criticality matrix.
DRAKON was used as a graphical modeling language for representation of cybersecurity case based on ASAC. It was developed from former USSR space program Buran (analogue of Space Shuttle). DRAKON, stands for "friendly algorithmic language that provides clarity." Initially DRAKON was developed for capturing requirements and building software that controls spacecraft [10]. As a language of requirements modeling was chosen IDEF0 notation. Notation IDEF0 allows to show the steps of the evaluation unambiguously (in the form of a directed graph), for each step to determine the evaluated property and evidences necessary for the evaluation, the subjects of assessment, and standards.

If the assessment is subject to a complex (composite) requirement, so each step (or block of IDEF0-diagram) can be decomposed for a detailed description of sub-properties evaluation procedure. 
Table 3. IMECA-analysis of attacks on FPGA-based I\&Cs.

\begin{tabular}{|c|c|c|c|c|c|c|c|c|}
\hline 운 & 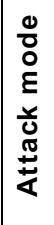 & 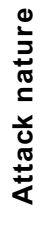 & Attack cause & 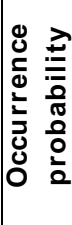 & 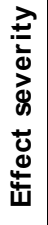 & Type of effects & $\begin{array}{l}\text { Countermeasures } \\
\text { (including RG 5.71) }\end{array}$ & $\begin{array}{l}\text { FPGA-based } \\
\text { I\&C diversity } \\
\text { kinds and its } \\
\text { attributes }\end{array}$ \\
\hline 1 & 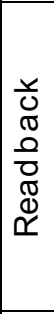 & $\frac{0}{\geq}$ & $\begin{array}{l}\text { Absence of chip } \\
\text { security bit and/ or } \\
\text { availability of } \\
\text { physical access to } \\
\text { chip interface (e.g., } \\
\text { JTAG) }\end{array}$ & M & $\mathrm{H}$ & $\begin{array}{l}\text { Obtaining of } \\
\text { secret } \\
\text { information by } \\
\text { adversary }\end{array}$ & $\begin{array}{l}\text { - The use of security bit; } \\
\text { - Application of physical } \\
\text { security controls; } \\
\text { (B.1.18 Insecure and } \\
\text { Rogue Connections, } \\
\text { Appendix B to RG 5.71, Page B- } \\
\text { 6) }\end{array}$ & $\begin{array}{l}\text { Diver sity of (EE): } \\
\text {-Different } \\
\text { technologies of EEs } \\
\text { production }\end{array}$ \\
\hline 2 & $\begin{array}{l}0 \\
\stackrel{0}{ \pm} \\
\frac{1}{0} \\
\frac{0}{0}\end{array}$ & $\frac{0}{\geq}$ & $\begin{array}{l}\text { Storing of decoded } \\
\text { configuration }\end{array}$ & $\mathrm{H}$ & $\mathrm{H}$ & $\begin{array}{l}\text { Obtaining of } \\
\text { configuration } \\
\text { data by } \\
\text { adversary }\end{array}$ & 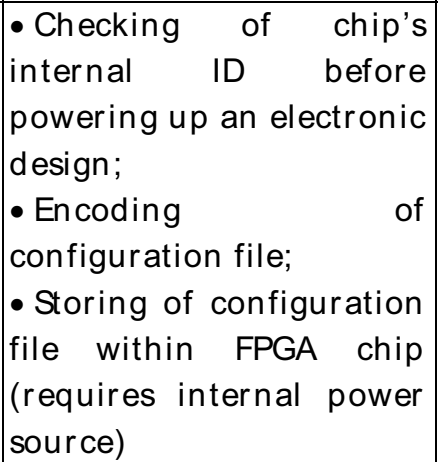 & $\begin{array}{l}\text { Diver sity of EE: } \\
\text {-Differ ent } \\
\text { technologies of EEs } \\
\text { production; } \\
\text {-Differ ent element } \\
\text { kinds of EE families }\end{array}$ \\
\hline 3 & 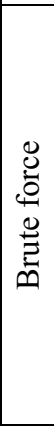 & $\frac{0}{\geq}$ & $\begin{array}{l}\text { - Search for a valid } \\
\text { output attempting } \\
\text { all possible key } \\
\text { values; } \\
\text { - Exhaustion of all } \\
\text { possible logic inputs to a } \\
\text { device in order; } \\
\text { - Gradual variation of the } \\
\text { voltage input and other } \\
\text { environmental conditions }\end{array}$ & L & M & $\begin{array}{l}\text { Leak of } \\
\text { und esirable } \\
\text { information }\end{array}$ & $\begin{array}{l}\text { Detecting and documenting } \\
\text { unauthorized changes to software } \\
\text { and information, } \\
\text { (C.3.7, Appendix C to RG 5.71, } \\
\text { Page C-7) }\end{array}$ & $\begin{array}{l}\text { Diversity of project } \\
\text { development languages } \\
\text { - Combination of couples } \\
\text { of diverse CASE-tools } \\
\text { and HDLs }\end{array}$ \\
\hline 4 & 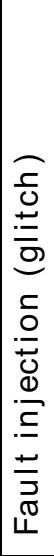 & 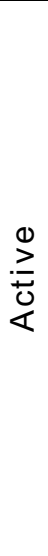 & $\begin{array}{l}\bullet \text { Altering the input } \\
\text { clock; } \\
\bullet \text { Creating } \\
\text { momentary over- } \\
\text { or } \\
\text { the } r \text { rer } r \text { shoots to } \\
\text { voltage }\end{array}$ & M & $\mathrm{H}$ & $\begin{array}{l}\bullet \text { Device to } \\
\text { execute an } \\
\text { incorrect } \\
\text { operation } \\
\text {-Device left in a } \\
\text { compromising } \\
\text { state } \\
\text { - Leak of secret } \\
\text { information }\end{array}$ & $\begin{array}{l}\bullet \text { Making sure all states } \\
\text { are defined and at the } \\
\text { implementation level, } \\
\text { verifying that glitches } \\
\text { cannot affect the order of } \\
\text { operations; } \\
\text {-Detection of voltage } \\
\text { tampering from within } \\
\text { the device; } \\
\text {-Clock supervisory } \\
\text { circuits to detect glitches }\end{array}$ & $\begin{array}{l}\text { Diversity of EE: } \\
\text {-Different } \\
\text { manufacturers of } \\
\text { EEs; } \\
\text {-Differ ent } \\
\text { technologies of EEs } \\
\text { production; } \\
\text { Diver sity of SS } \\
\text {-Different SSs; } \\
\text {-Combination of } \\
\text { diverse CASE tools } \\
\text { and SSs }\end{array}$ \\
\hline
\end{tabular}

\subsection{Building of ASAC}

The result of the analysis of requirements of assurance class "Vulnerability analysis" AVA VAN.3 from International Standard ISO/IEC 15408 is presented in the form of ontological graph (see Fig. 4). The graph accurately and unambiguously (in the accepted notation) describes the subject area (i.e. basic notions/concepts and relations between them). It contains diversity requirements for ensuring of cybersecurity of I\&Cs (as countermeasures, Table 3) marked in light-blue fillings.

Completeness of scope of assessment is ensured by using ontological graphs of two kinds of object-oriented and process-oriented ontology. Requirements of assurance class "Vulnerability analysis" AVA_VAN.3 from IEC 15408 are depicted in form of properties (Fig. 5), evidences (Fig. 6) and corresponding actions of an 
expert (Fig. 7) as results of ontological analysis of diversity requirements for secure I\&Cs (marked with blue and dark-blue) and represented in established ASAC form on figure.

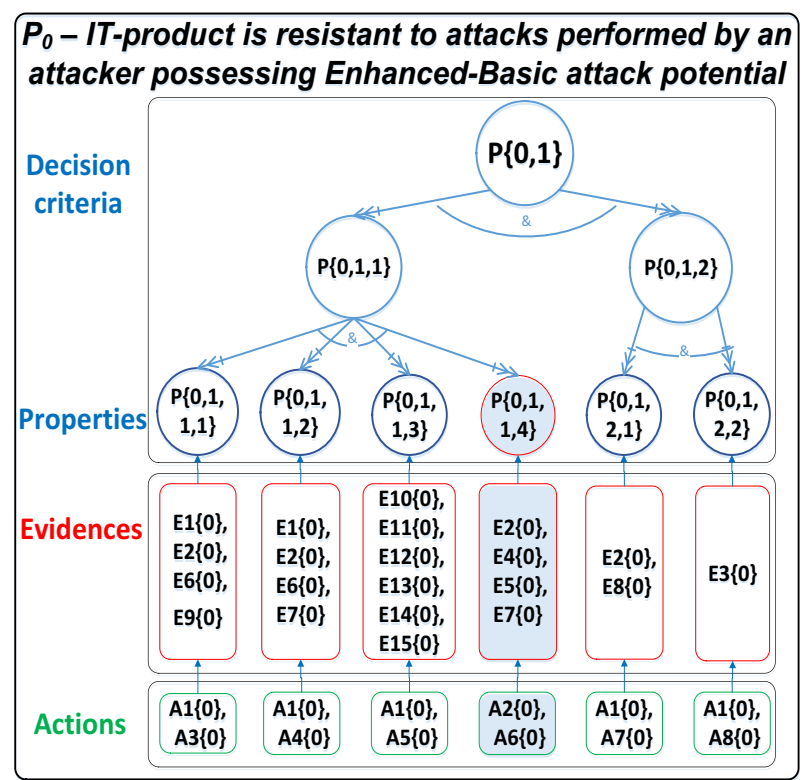

Figure 4. Ontological model in form of graph.

\begin{tabular}{|c|c|}
\hline$P\{J\}$ & PROPERTIES \\
\hline$P\{0\}$ & $\begin{array}{l}\text { Resistant of the TOE to attacks performed by an attacker possessing } \\
\text { Basic attack potential }\end{array}$ \\
\hline$P\{0,1\}$ & Readiness of the TOE for testing \\
\hline $\mathrm{P}\{0,1,1\}$ & Consistent of the TOE with ST \\
\hline$P\{0,1,1,1\}$ & $\begin{array}{l}\text { Conformity of the TOE reference with the CM capabilities (ALC_CMC) } \\
\text { sub-activities and ST introduction }\end{array}$ \\
\hline$P\{0,1,1,2\}$ & Consistent of the all TOE configurations with ST \\
\hline$P\{0,1,1,3\}$ & $\begin{array}{l}\text { Conformity of the testing environment to the security objectives for } \\
\text { the operational environment described in the ST }\end{array}$ \\
\hline $\mathrm{P}\{0,1,1,4\}$ & Conformity of the TOE to diversity requirements \\
\hline$P\{0,1,2\}$ & Accuracy of the TOE installing \\
\hline$P\{0,1,2,1\}$ & Successfulness completion of the AGD_PRE.1 \\
\hline \} & $\begin{array}{l}\text { Successfulness of the TOE install and start up, using the supplied } \\
\text { guidance only }\end{array}$ \\
\hline
\end{tabular}

Figure 5. Properties of ASAC represented in tabular form.

\begin{tabular}{|c|l|}
\hline$E I\{J\}$ & \multicolumn{1}{|c|}{ EVIDENCES } \\
\hline$E 1\{0\}$ & TOE is suitable for testing \\
\hline$E 2\{0\}$ & Security Target \\
\hline$E 3\{0\}$ & Guidance documentation \\
\hline$E 4\{0\}$ & $\begin{array}{l}\text { Information is publicly available to support the identification of } \\
\text { potential vulnerabilities }\end{array}$ \\
\hline$E 5\{0\}$ & $\begin{array}{l}\text { Current information regarding potential vulnerabilities (e.g. from an } \\
\text { evaluation authority) }\end{array}$ \\
\hline$E 6\{0\}$ & Basic functional specification \\
\hline$E 7\{0\}$ & Security architecture description \\
\hline$E 8\{0\}$ & Implementation representation of the TSF \\
\hline$E 90\}$ & Basic modular design \\
\hline$E 10\{0\}$ & Applicability of different technologies of EEs production \\
\hline$E 11\{0\}$ & Applicability of different element kinds of EE families \\
\hline$E 12\{0\}$ & Applicability of different manufacturers of EEs \\
\hline$E 13\{0\}$ & Applicability of different SSs \\
\hline$E 14\{0\}$ & Applicability of combination of diverse CASE tools and SSS \\
\hline$E 15\{0\}$ & $\begin{array}{l}\text { Applicability of combination of couples of diverse CASE-tools and } \\
\text { HDLs }\end{array}$ \\
\hline
\end{tabular}

Figure 6. Evidences of ASAC represented in tabular form.

\begin{tabular}{|c|l|}
\hline Ai $\{J\}$ & \multicolumn{1}{|c|}{ ACTIONS } \\
\hline $\mathbf{A} 1\{0\}$ & Obtain the evidences \\
\hline $\mathbf{A} 2\{0\}$ & Obtain the diversity applicability evidences \\
\hline $\mathbf{A} 3\{0\}$ & $\begin{array}{l}\text { Check the conformity of the TOE reference with the CM capabilities } \\
\text { (ALC_CMC) sub-activities and ST introduction }\end{array}$ \\
\hline $\mathbf{A} 4\{0\}$ & Check the consistent of the all TOE configurations with ST \\
\hline $\mathbf{A 5}\{0\}$ & $\begin{array}{l}\text { Check the conformity of the testing environment to the security } \\
\text { objectives for the operational environment described in the ST }\end{array}$ \\
\hline $\mathbf{A} 6\{0\}$ & Check the conformity of the TOE to diversity requirements \\
\hline $\mathbf{A} 7\{0\}$ & Check the successfulness completion of the AGD_PRE.1 \\
\hline $\mathbf{A} 8\{0\}$ & $\begin{array}{l}\text { Check the successfulness of the TOE install and start up, using the } \\
\text { supplied guidance only }\end{array}$ \\
\hline
\end{tabular}

Figure 7. Actions of ASAC represented in tabular form.

\section{Conclusions}

The paper describes cybersecurity assurance technique of multi-version FPGA-based I\&Cs. Requirements profile is formulated using the best practices from the following international regulations. The paper summarizes research results on using of security informed safety assessment of FPGA-based MV I\&Cs by development of security case based on ASAC. This case considers requirements from Common Criteria and added requirements for diversity as a countermeasure and CCF risk reduction strategy.

Security assurance case tends to reducing of uncertainty of safety assessment taking into account influence of security (cybersecurity) to safety.

It is characterized by introduction of technique of decision making, which is easy to scale, modify, it's in compliance with standards requirements to the

Future steps of research and development will be connected with creation integrative intsrumentation tool to assess secuirty and safety at the all life cycle stages considering features of FPGA-based industrial I\&Cs where application of diversity is defined by standard requirements. Other direction of future work is concerned to improve and completely assure computer-based implementation of ASAC-based technique.

\section{References}

1. V. Sklyar, Cyber Security of Safety-Critical Infrastructures: A Case Study for Nuclear Facilities, Information \& Security An international Journal, 28, 1 (2012)

2. V. Kharchenko, O. Illiashenko, A. Kovalenko, et. al. Security Informed Safety Assessment of NPP I\&C Systems: GAP-IMECA Technique, ICONE 22, Prague, Czech Republic (2014)

3. B. Badrignans, J. Danger, V. Fischer, G. Gogniat, L. Torres, Security Trends for FPGAs (Springer, 2011)

4. T. Huffmire, C. Irvine, T. Nguyen, T. Levin, R. Kastner, T. Sherwood, Handbook of FPGA Design Security (Springer, 2010)

5. M. Tehranipoor, C. Wang (edits), Introduction to Hardware Security and Trust (Springer, 2012)

6. NUREG/CR-7007 ORNL/TM-2009/302 (2009)

7. V. Kharchenko, V. Sklyar (edits). FPGA-based NPP Instrumentation and Control Systems: Development and Safety Assessment, (KhAI , 2008) 
8. M. Yastrebenetsky, V. Kharchenko (edits). NPP I\&S for Safety and Security, (IGI-Global, USA, 2014)

9. O. Illiashenko, O. Potii, D. Komin. Advanced security assurance case based on ISO/IEC 15408, DepCoS-RELCOMEX, Brunów, Poland (2015)

10. V. Parondzhanov, How to improve the work of your mind (Delo, Russia, 2001)

11. N. G. Bardis, N. Doukas, O. P. Markovski. Burst Error Correction Using Binary Multiplication without Carry, MILCOM 2011 Military Communications Conference, Baltimore, MD (2011) 